\title{
Alcohol Consumption and Breast Cancer Risk among Women in Three Sub-Saharan African Countries
}

\section{Frank Qian ${ }^{19}$, Temidayo Ogundiran ${ }^{29}$, Ningqi Hou ${ }^{3}$, Paul Ndom ${ }^{4}$, Antony Gakwaya ${ }^{5}$, Johashaphat Jombwe ${ }^{5}$, Imran Morhason-Bello ${ }^{6}$, Clement Adebamowo7, Adeyinka Ademola ${ }^{2}$, Oladosu Ojengbede ${ }^{6}$, Olufunmilayo I. Olopade ${ }^{1}$, Dezheng Huo ${ }^{3 *}$}

1 Center for Clinical Cancer Genetics and Global Health, Department of Medicine, University of Chicago, Chicago, Illinois, United States of America, 2 Department of Surgery, College of Medicine, University of Ibadan, Ibadan, Nigeria, 3 Department of Health Studies, University of Chicago, Chicago, Illinois, United States of America, 4 Medical Oncology Service, Yaoundé General Hospital, Yaoundé, Cameroon, 5 Mulago Hospital, Makerere University, Kampala, Uganda, 6 Center for Population and Reproductive Health, University College Hospital, Ibadan, Nigeria, 7 Department of Epidemiology and Public Health, University of Maryland, Baltimore, Maryland, United States of America

\begin{abstract}
Background: Alcohol drinking is linked to the development of breast cancer. However, there is little knowledge about the impact of alcohol consumption on breast cancer risk among African women.

Methods: We conducted a case-control study among 2,138 women with invasive breast cancer and 2,589 controls in Nigeria, Cameroon, and Uganda from 1998 to 2013. A structured questionnaire was used to collect information on alcohol consumption, defined as consuming alcoholic beverages at least once a week for six months or more. Logistic regression was used to estimate adjusted odds ratio (aOR) and 95\% confidence interval (CI).

Results: Among healthy controls, the overall alcohol consumption prevalence was $10.4 \%$, and the prevalence in Nigeria, Cameroon, and Uganda were $5.0 \%, 34.6 \%$, and 50.0\%, respectively. Cases were more likely to have consumed alcohol $(\mathrm{aOR}=1.62,95 \% \mathrm{Cl}: 1.33-1.97)$. Both past $(\mathrm{aOR}=1.54 ; 95 \% \mathrm{Cl}: 1.19-2.00)$ and current drinking $(\mathrm{aOR}=1.71 ; 95 \% \mathrm{Cl}: 1.30-2.23)$ were associated with breast cancer risk. A dose-response relationship was observed for duration of alcohol drinking $(P$-trend $<0.001$ ), with 10-year increase of drinking associated with a $54 \%$ increased risk (95\% Cl: 1.29-1.84).
\end{abstract}

Conclusion: We found a positive relationship between alcohol consumption and breast cancer risk, suggesting that this modifiable risk factor should be addressed in breast cancer prevention programs in Africa.

Citation: Qian F, Ogundiran T, Hou N, Ndom P, Gakwaya A, et al. (2014) Alcohol Consumption and Breast Cancer Risk among Women in Three Sub-Saharan African Countries. PLoS ONE 9(9): e106908. doi:10.1371/journal.pone.0106908

Editor: Olivia Fletcher, The Institute of Cancer Research, United Kingdom

Received May 9, 2014; Accepted August 5, 2014; Published September 8, 2014

Copyright: $\odot 2014$ Qian et al. This is an open-access article distributed under the terms of the Creative Commons Attribution License, which permits unrestricted use, distribution, and reproduction in any medium, provided the original author and source are credited.

Data Availability: The authors confirm that, for approved reasons, some access restrictions apply to the data underlying the findings. To protect the confidentiality of patients and controls in the study, we are obligated not to put the data in a public repository. However, our data relevant to this manuscript are available upon request. Individuals interested in the data can contact Ms. Fang Liu (fliu3@medicine.bsd.uchicago.edu) or Ms. Diane Houdek (dhoudek@medicine. bsd.uchicago.edu).

Funding: The study was supported by grants from the National Cancer Institute of National Institutes of Health (CA-RO1 89085-01A and P50 CA125183), the Dr. Ralph and Marian Falk Medical Research Trust, and Avon Foundation for Women (URL: http://www.avonfoundation.org/). The funders had no role in study design, data collection and analysis, decision to publish, or preparation of the manuscript.

Competing Interests: The authors have declared that no competing interests exist.

*Email: dhuo@uchicago.edu

9 These authors contributed equally to this work.

\section{Introduction}

Breast cancer is a leading cause of cancer morbidity and mortality for women world-wide $[1,2,3,4,5,6]$. In recent decades, breast cancer incidence has seen a steady increase in many developing countries while it reached a plateau in developed nations $[6,7,8]$. Alcohol consumption has been considered a plausible risk factor for breast cancer. This relationship has been confirmed in some studies $[9,10,11,12,13,14,15]$, but not in others $[16,17,18,19]$. However, the majority of these studies were conducted among women in high income countries $[9,18,20,21,22]$, with few in developing countries [19,23,24]. To our knowledge, there is no large study on alcohol intake and breast cancer conducted in Africa. Studies of the relationship between alcohol consumption and breast cancer risk among African Americans have found inconclusive results $[16,25,26,27,28]$. The extent of alcohol drinking's effect on breast cancer risk may vary across races, possibly due to different drinking habits, metabolism and genetic factors. In general, alcohol drinking is less common among African women than their counterparts in North America and Europe [29], but the prevalence rates vary by country in Africa: ever drinking prevalence ranges from $<1 \%$ to over $40 \%$ and current drinking prevalence ranges from none to nearly $30 \%$ $[29,30,31]$. The general trend among African women is towards greater prevalence of alcohol consumption [29,32]. 
Most studies of alcohol and breast cancer have assessed alcohol use in terms of ever-drinking versus nondrinking or the average daily dose [33]. Other patterns of alcohol use such as duration of alcohol consumption or age when first started drinking and their relationship to breast cancer risk are less well understood [12]. We conducted a case-control study of alcohol consumption patterns and breast cancer risk among women in three sub-Saharan African countries: Nigeria, Cameroon, and Uganda.

\section{Materials and Methods}

\section{Study population}

The African Breast Cancer Study was originally started in Nigeria in 1998 and was expanded to Uganda and Cameroon in 2011 using the same questionnaire and protocol. The study protocol was reviewed by the institutional review boards of the three sites and the University of Chicago (University of Chicago Biological Sciences Division Institutional Review Board (13304B and 10-023-B), University of Ibadan/University College Hospital Ethics Committee (UI/IRC/02/0003), Cameroon National Ethics Committee (N141/CNE/SE/2010), and Makerere University College of Health Sciences Ethics Committee (2011-023)). The study setting and design at the Nigeria site are described in detail elsewhere [34,35,36]. Briefly, cases were identified through University College Hospital (UCH), University of Ibadan, in Ibadan, Nigeria. Serving a population of more than 3 million people, UCH is a referral center for other hospitals and thus treat the majority of breast cancer cases in the region. All consecutive females who were 18 years or older, black of African descent, capable of providing informed consent, and had a histologic or clinical diagnosis of invasive breast cancer were recruited through the surgical oncology and radiotherapy units of the UCH. Controls were females aged 18 years or older, absent of breast cancer, and able to give informed consent. During the period of case enrollment, several communities were randomly selected by ballot from the list of all the communities in catchment area of $\mathrm{UCH}$ and considered to be stable, socio-economically and ethnically diverse, and represent $\mathrm{UCH}$ patients. Field interviewers randomly approached households in these communities and invited eligible women to visit community centers for the study. We also enrolled clinical controls through general outpatient and ophthalmology clinics in the UCH, matched for age and ethnicity. Women were enrolled during their waiting in clinics and they are unselected for their medical conditions. As the characteristics of hospital-based and community controls were similar, they were pooled in the further analysis. In Uganda, cases were identified at the breast and endocrine unit in department of surgery of the Mulago Hospital, Makerere University in Kampala. Mulago Hospital is a national referral hospital in Uganda and serves the 1.3 million residents in Kampala. Controls were randomly recruited from the general outpatient clinics and surgical ward admissions at Mulago Hospital, matched to cases for age and ethnicity. In Cameroon, breast cancer cases were enrolled at the department of medical oncology of Yaoundé General Hospital, Yaoundé University I in Yaoundé. Yaoundé General Hospital serves a population of 2.5 million people. Controls were randomly recruited from the clinics of general medicine and obstetrics and gynecology departments at the same hospital, matched to cases for age and ethnicity. At the Kampala and Yaoundé sites, hospital controls were unselected for their medical conditions. All study participants provided written informed consent prior to their interview. During the recruitment, both patients and controls were enthusiastic to participate in the study, with a response rate of $>$ $90 \%$.

\section{Data collection and measures}

Trained interviewers at the three sites performed structured questionnaire interviews, measured height and weight, and obtained blood samples. The questionnaire included questions about demographics, family history of breast cancer and history of benign breast disease, lifestyle factors, menstrual and reproductive history, and alcohol consumption patterns.

Before 2006, alcohol consumption was asked in Nigeria in terms of average volume of alcohol consumed per week (among 1,492 women). After 2006, the measurement was changed to average number of drinks per week. In Uganda and Cameroon, the alcohol consumption was asked in terms of average number of drinks per week. To convert the amount of alcohol into a common unit, the following conversion criteria were used: $350 \mathrm{~mL}$ bottle of beer $(5 \%$ alcohol volume) $\approx 150 \mathrm{~mL}$ glass of wine (including local wine such as tonto or ajon in Uganda, $15 \%$ alcohol) $\approx 50 \mathrm{~mL}$ shot of spirits (including local spirits such as waragi or enguli in Uganda, $40 \%$ alcohol) $\approx 18 \mathrm{~mL}$ pure ethanol, which is equivalent to one standard drink. We then summed the amount of pure ethanol the participant consumed irrespective of the type of drink. We subsequently converted the volume of pure ethanol to gram: $1 \mathrm{~mL}=0.8$ gram. Each standard drink is hence equivalent to about 14.4 grams of pure ethanol. We also constructed a new variable called the life-time alcohol consumption, which was defined as gram-years: the average daily amount of alcohol in grams was multiplied by the subject's duration of alcohol consumption in years.

We defined alcohol drinking as having ever consumed alcoholic beverages at least once a week for continuous six months or more. In addition, we measured other alcohol drinking patterns: status of drinking (never drank, past drank, and current drinking; current drinking is defined as consuming alcohol at least once a week up until one year before breast cancer diagnosis or interview date), age at first drink, duration of alcohol drinking, and average amount of alcohol consumed daily. Duration of alcohol drinking was grouped into four categories: never drank, 1-9, 10-19, and $\geq$ 20 years. Average amount of alcohol consumed daily was also grouped into four categories: never drank, $0.1-4.9,5.0-9.9$, and $\geq$ 10.0 grams. Age at first drink had five categories: never drank, $\leq$ 18, 19-24, 25-29, and $\geq 30$ years. Life-time alcohol consumption was also categorized into five groups: never drank, 0.1-29.9, 30.079.9 , 80.0-159.9, and $\geq 160.0$ gram-years.

\section{Statistical analyses}

Demographic factors and potential confounding factors for breast cancer were compared between cases and controls using student $t$-test or Wilcoxon rank-sum test for continuous variables and $\chi^{2}$ test or Fisher's exact test for categorical variables. All Pvalues reported are two-sided. We calculated the percentages of control women who were currently consuming alcohol by the age groups of $18-34,35-44,45-54$, and $\geq 55$ years.

Multiple logistic regression models were used to examine the association between breast cancer and various patterns of alcohol consumption while adjusting for study site and other potential confounders listed below. These confounders were adjusted for in every multivariable logistic regression model and were defined as follows: age at diagnosis or interview (5-year interval categories), ethnicity (Yoruba, Ibo, Hausa, Baganda, Bantous, Semi-Bantous, others), education (none, elementary, secondary, some college or above, and vocational), age at menarche ( $\leq 14,15-16,17-18, \geq$ 19 year), family history of breast cancer (yes, no), history of benign breast disease (yes, no), hormonal contraceptive use (ever, never), fertility drugs (ever, never), height, body mass index (BMI, $\mathrm{kg} / \mathrm{m}^{2}$ ), menopausal status (premenopausal, natural postmenopausal, 


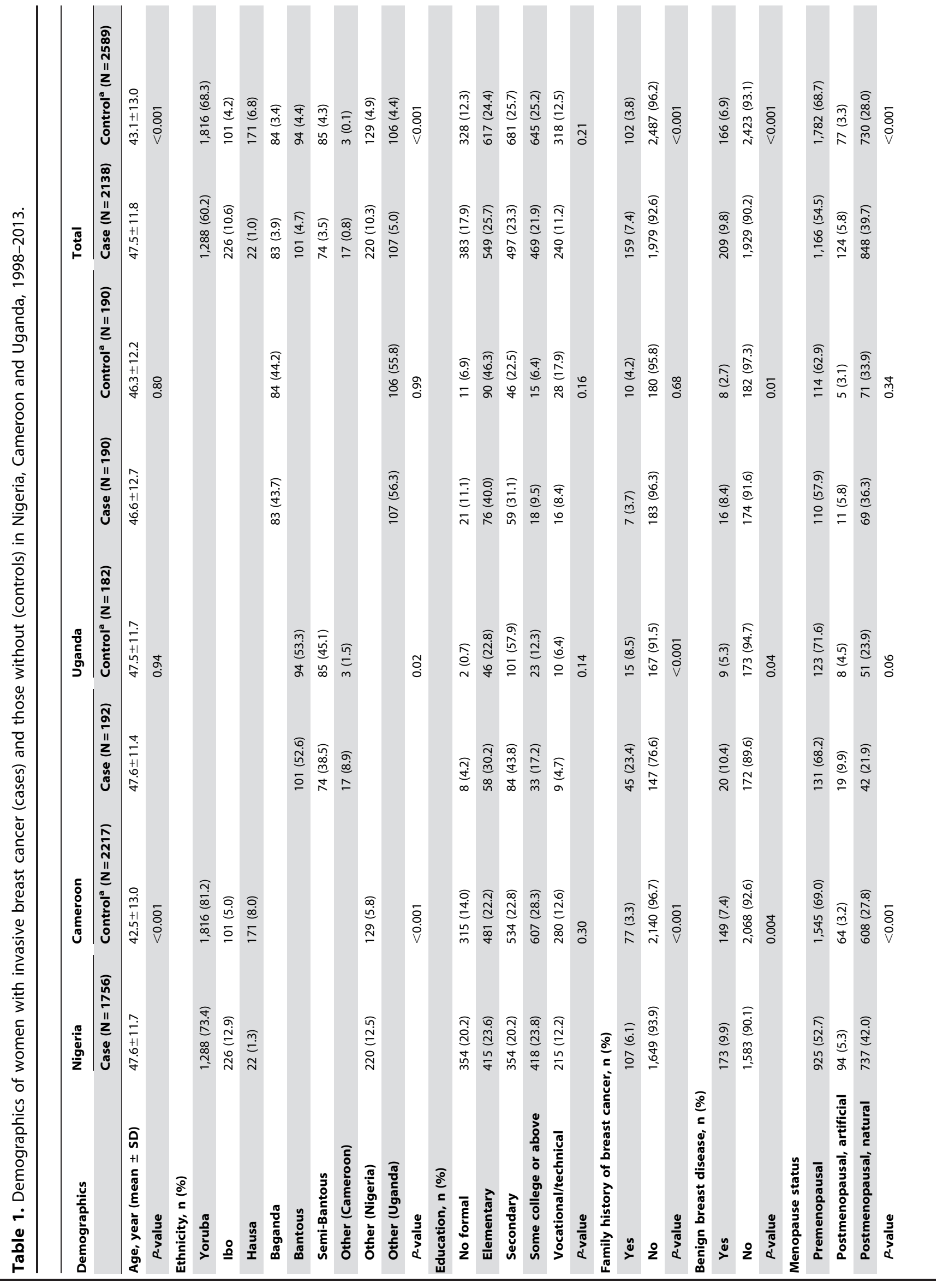




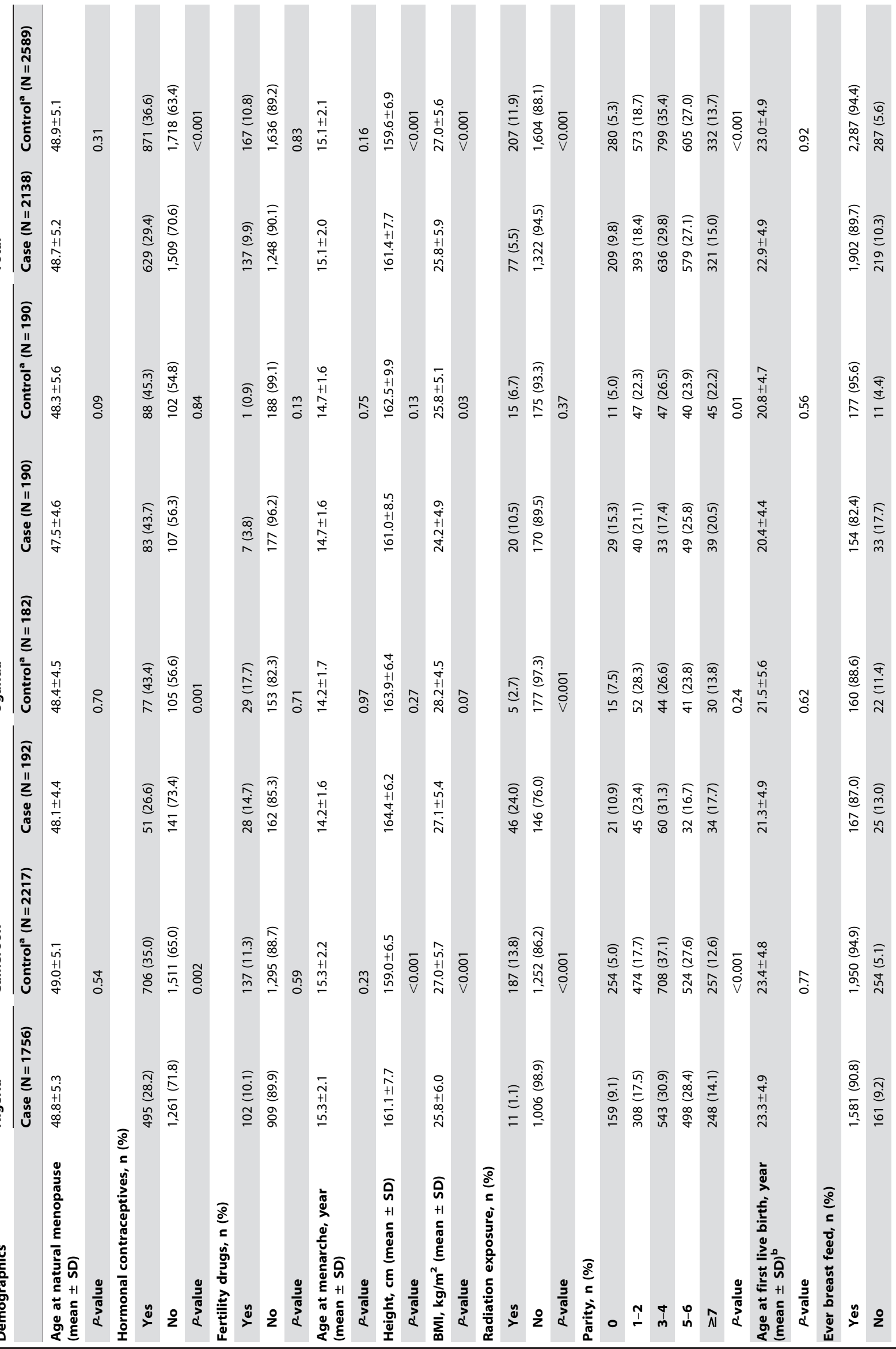




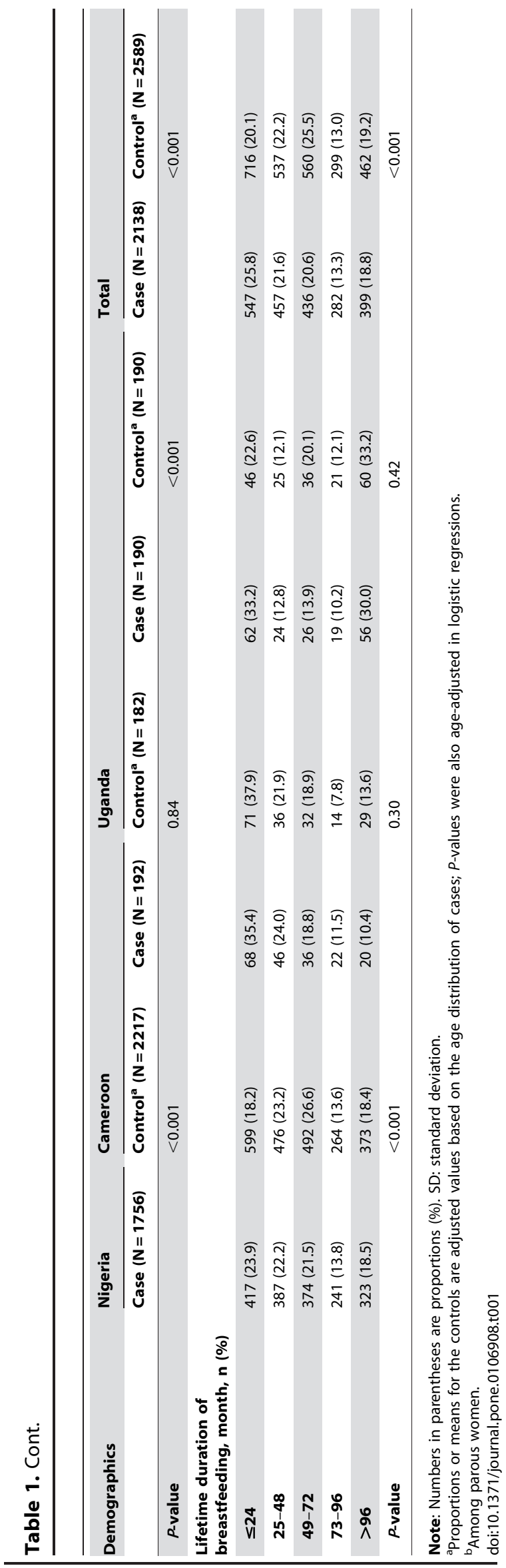

artificial postmenopausal), age at first live birth $(<20,20-24,25-$ 29 , $\geq 30$ years), and parity $(0,1-2,3-4,5-6, \geq 7)$. Adjusted odds ratio (aOR) and 95\% confidence interval (CI) were computed from the logistic regression models. Ever drank, status of drinking, and type of alcohol consumed (never drank, beer, wine, spirits) were included in the models solely as categorical variables. Age at first drink, duration of alcohol drinking, average amount of alcohol consumed daily, and life-time alcohol consumption were analyzed as both categorical variables and continuous variables. Stratified analyses were also performed to compare the breast cancer risk between ever-drinkers vs. never-drinkers across different strata of demographic and reproductive variables, such as premenopausal vs. post-menopausal women. Potential confounding variables were adjusted for in these analyses.

There were missing data for age at first drink, duration of alcohol drinking, average volume of drinking, and other important covariates. To use all available information and avoid bias due to list-wise deletion in the multivariable analysis, we conducted multiple imputations via chained equations approach for imputation $[37,38]$. All covariates and outcome variable (case-control status) were included in the imputation model. We ran 100 imputations to improve statistical efficiency of the imputation estimates to be over 99.5\%. The logistic regression models described above were fitted using each of the imputed data sets. Results across the multiply imputed datasets were combined according to Rubin's rules [39]. Multiple imputation approach assumes missing at random. Older women tended to forget how much alcohol they consumed in the past. By including age in the multiple imputation models, it is reasonable to believe that the probability of missing alcohol data was at random. As a sensitivity analysis, we conducted the analysis using data without missing value in any of the covariates in the models (i.e. complete case analysis). All statistical analyses, including the imputation (ice module), were conducted with STATA 13.0 (StataCorp, College Station, TX, USA).

\section{Results}

A total of 2,138 breast cancer cases and 2,589 controls (women without breast cancer) were enrolled in the study between March 1998 and July 2013, including 1,756 cases and 2,217 controls in Nigeria, 192 cases and 182 controls in Cameroon, and 190 cases and 190 controls in Uganda. Table 1 shows selected demographic and reproductive characteristics of study participants. Since Nigeria comprises the largest proportion of the study population, demographic differences between cases and controls in the Nigerian population will influence the difference in the overall population. Cases in Nigeria were 5.1 years older than controls on average; there was no difference in age between cases and controls in Cameroon or Uganda. Most participants in Nigeria were Yoruba, and over half of the participants in Uganda were Baganda and in Cameroon were Bantous. In all study participants, about $40 \%$ had less than a secondary education. About $75 \%$ of women had $\geq 3$ live births. There were no differences between cases and controls in terms of their average age at menarche and use of fertility drugs in the crude analysis. In the Nigerian population, cases were taller than controls, on average. Cases were more likely to have a family history of breast cancer and a history of benign breast disease in Nigeria and Cameroon. Similarly, controls were more likely to have ever used hormonal contraceptives. In the Cameroon population, the proportion of cases who had a family history of breast cancer $(23.4 \%)$ was considerably larger than the controls $(8.2 \%)$. This difference was less pronounced in Nigeria 


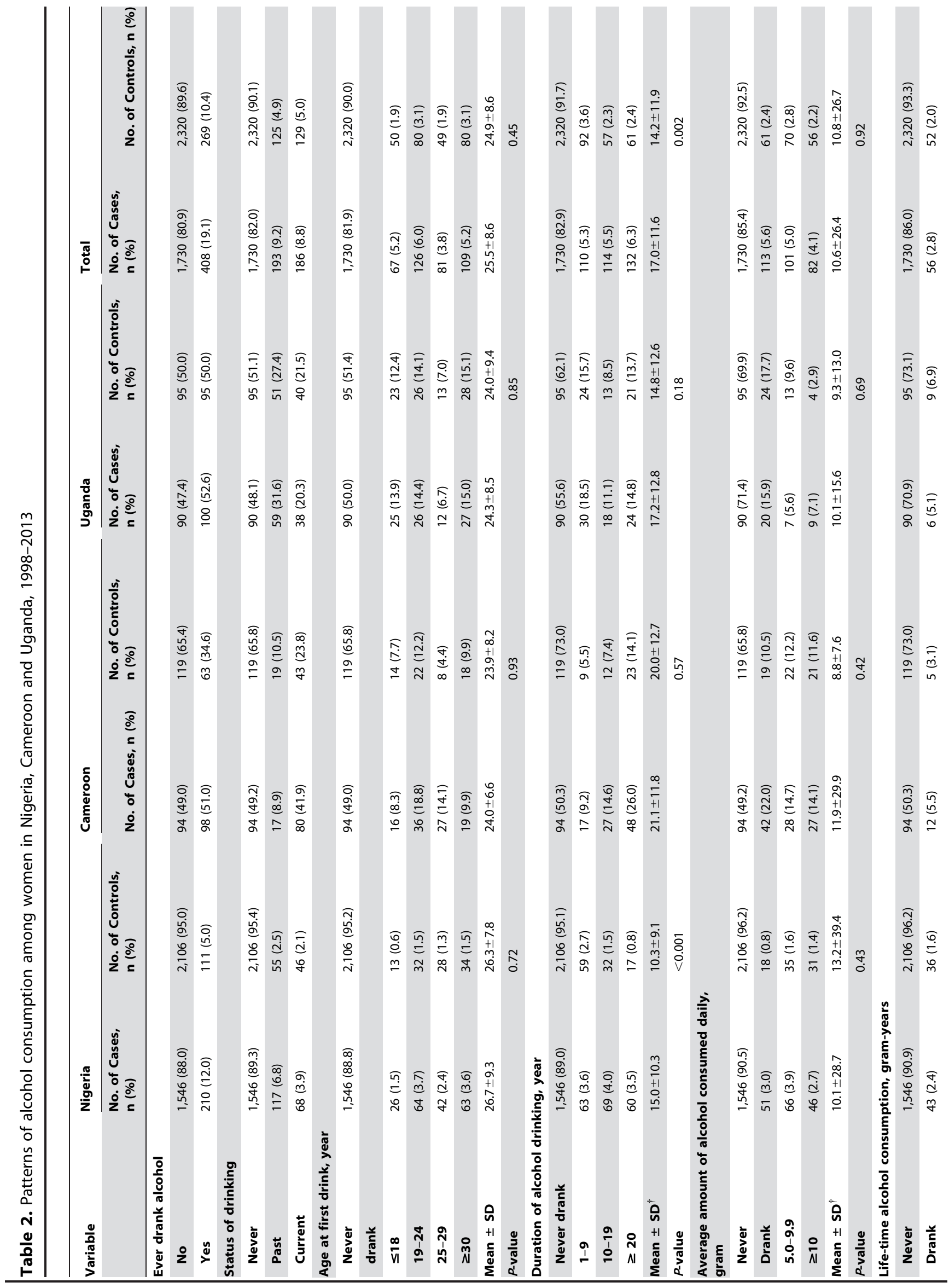




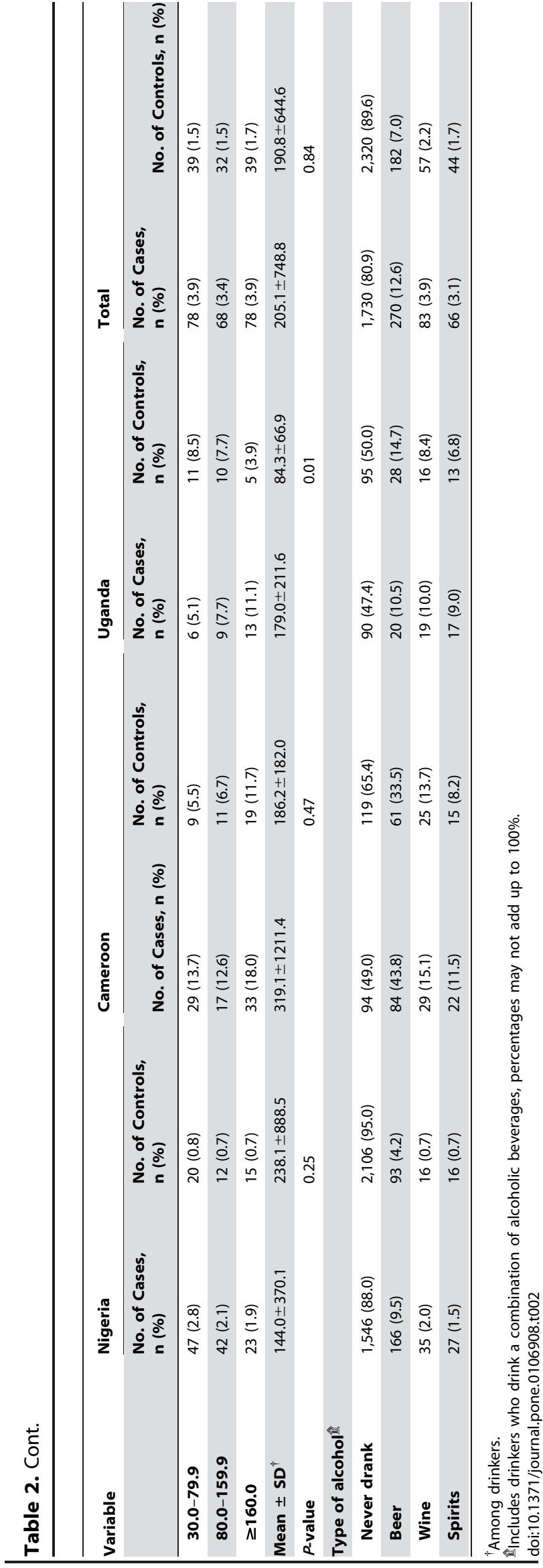

and Uganda, though the difference was still statistically significant in Nigeria.

Overall, there were $1,311(1.7 \%)$ missing values across 16 variables in Tables 1 and 2 (excluding derivative variables). Complete information was available for ethnicity, ever drink alcohol, menopausal status, and site of study. About $5 \%$ of participants had a missing value for age at menarche, and 3\% of them had missing values for height and weight. Data were occasionally missing for other variables as well. One hundred data sets were generated by multiple imputation such that the efficiency of estimating OR was greater than $99.5 \%$ for the fraction of missing information up to 0.08 .

Among healthy controls, $10.4 \%$ were alcohol drinkers, and the percentage of ever drinkers in Cameroon, Nigeria, and Uganda were $34.6 \%, 5.0 \%$, and $50.0 \%$, respectively. Figure 1 shows the percentages of current alcohol drinking among women by age group. Women in Cameroon and Uganda were more likely to be current drinkers than those in Nigeria. Among women in Cameroon and Nigeria, current drinking was proportionately more common in middle-aged women (aged 35-44 and 45-54 years) than younger or older women, while in Uganda, young women (aged 18-34) had the highest prevalence of current drinking.

Table 2 presents the alcohol drinking patterns among cases and controls. There was no statistical difference in the mean age at first drink and mean amount of alcohol consumed daily in the overall data. In terms of duration of alcohol consumption, cases were found to drink for 2.8 years longer on average than in controls. In the overall population, $86.4 \%$ of drinkers consumed $\leq 1$ drink per day ( 1 drink $=14.4 \mathrm{~g}$ of pure ethanol), $8.8 \%$ of drinkers consumed 1-2 drinks per day, $2.8 \%$ of drinkers consumed 2-3 drinks per day, and $2.1 \%$ of drinkers consumed more than 3 drinks per day. In drinkers, there was no considerable difference in amount of alcohol drinking among the three countries.

Table 3 presents the relationship of the alcohol drinking patterns to breast cancer risk with calculated odds ratio and 95\% CI using imputed data. Among the whole study sample, cases were more likely than controls to have ever consumed alcohol (aOR: 1.62, 95\% CI: 1.33-1.97). Both past drinking (aOR: 1.54; 95\% CI: 1.19-2.00) or current drinking (aOR: 1.71; 95\% CI: 1.30-2.23) were associated with increased breast cancer risk. Breast cancer risk was relatively consistent regardless of when the women first started drinking. Compared with non-drinkers, women who had drunk for $<10$ years had $41 \%$ higher odds of having breast cancer (aOR: 1.41; 95\% CI: 1.04-1.91), and those who had drunk for $10-19$ years had $71 \%$ (aOR: 1.71 ; 95\% CI: 1.23-2.39) and those for $\geq 20$ years had $82 \%$ (aOR: 1.82 ; 95\% CI: 1.30-2.54) higher odds of having breast cancer. Every 10-year increase in the duration of drinking was associated with a $54 \%$ increase in breast cancer risk (aOR: 1.54; 95\% CI: 1.29-1.84; $P$ trend: $<0.001)$. We also found that alcohol consumption was associated with breast cancer risk, regardless of alcohol amount; breast cancer risk increase was shown even in the category of women who consume $0.1-4.9 \mathrm{~g} /$ day (aOR: 1.82 , 95\% CI: $1.31-$ 2.54). In the variable life-time alcohol consumption, increased breast cancer risk was observed for subjects who consume at least 30 gram-years or more of alcohol (aOR: 1.85, 95\% CI: 1.26-2.72). We also found a statistically significant trend, with each 100 gramyears contributing a $29 \%$ increase in breast cancer risk (aOR: 1.29; 95\% CI: $1.12-1.51 ; P$-trend $=0.001)$. The complete case analysis, in which subjects with missing values in any of the variables in the models were dropped, showed similar study findings (Table $\mathrm{S} 1$ ). 


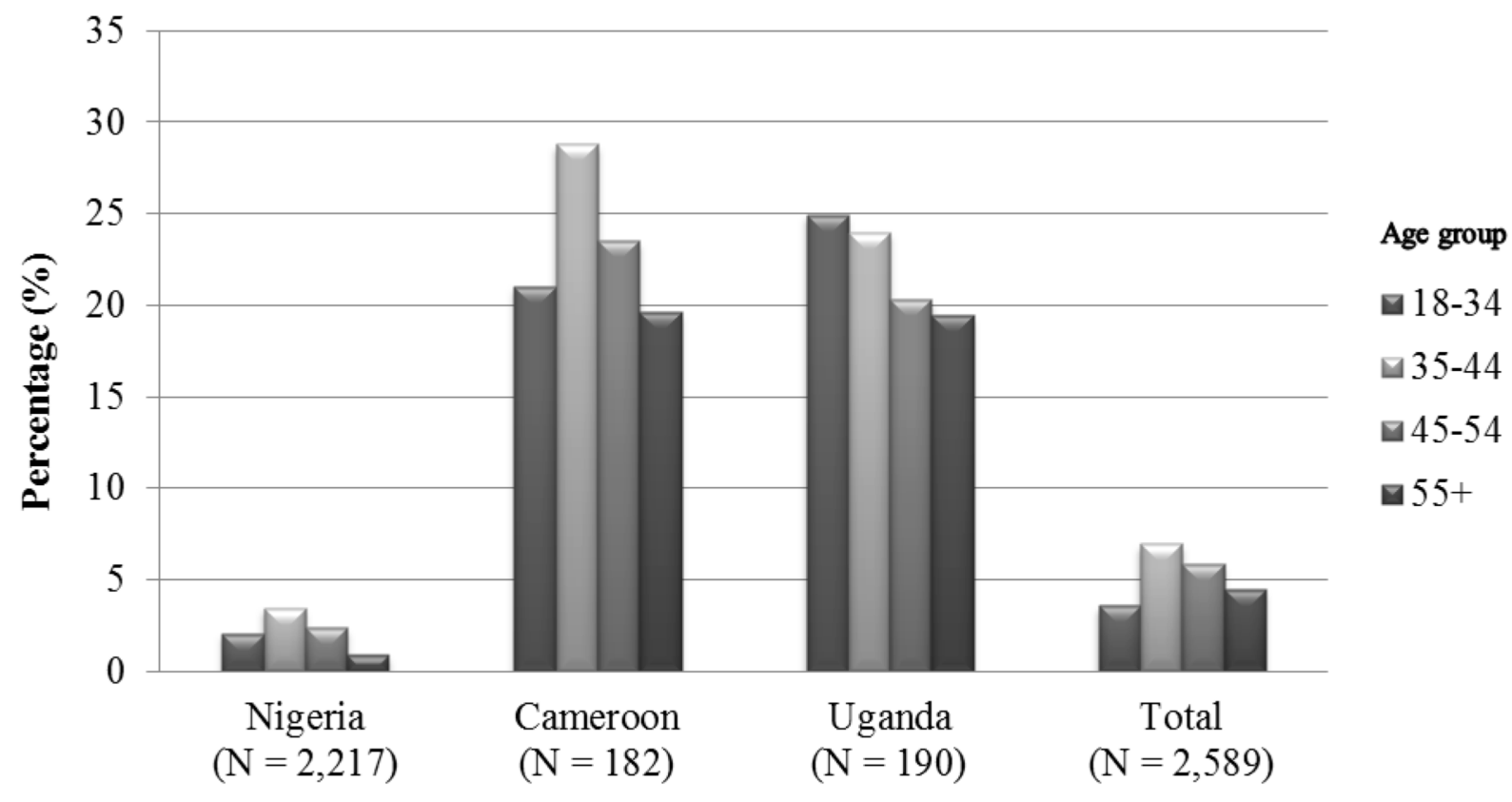

Figure 1. Percentage of healthy controls who were current drinkers by age group in the three African countries. doi:10.1371/journal.pone.0106908.g001

Table 4 shows the relationship between ever-drinking and breast cancer risk by strata of age at interview or diagnosis, ethnicity, height and other demographic and reproductive variables. When the interactions between the stratified variables and ever drinking alcohol were tested, parity and BMI were found to have a statistically significant interaction with alcohol drinking $(P=0.03$ for both tests). In parous women, the association between drinking alcohol and breast cancer was weaker (aOR: 1.55; 95\% CI: $1.26-1.91)$ than that in nulliparous women (aOR: $2.81 ; 95 \%$ CI: $1.24-6.35)$. There was no statistically significant association between alcohol consumption and breast cancer among women with $\mathrm{BMI} \leq 25 \mathrm{~kg} / \mathrm{m}^{2}$ (aOR: 1.09; 95\% CI: 0.79-1.50), while among women with BMI $>25 \mathrm{~kg} / \mathrm{m}^{2}$, ever-drinkers had nearly twice the odds for breast cancer than never-drinkers (aOR: 2.06, 95\% CI: 1.59-2.68). For other stratification variables, drinkers had similarly elevated risks for breast cancer compared to non-drinkers across the strata of these variables.

\section{Discussion}

Our case-control study of 4,727 African women from Nigeria, Cameroon, and Uganda showed a positive relationship between breast cancer and alcohol drinking. Overall, the odds of having breast cancer were $62 \%$ higher among women who ever consumed alcohol than among no-drinkers. This finding was in general agreement with literature. The current evidence on the relationship between alcohol consumption and female breast cancer risk is largely based on studies conducted in Caucasian populations $[40,41]$, and the observed evidence in African American women was inconsistent [17,18,42,43]. Numerous reasons may explain for the racial difference, including drinking habits, metabolism and genetic factors. For example, there are racial differences in distributions of genetic polymorphisms related to ethanol metabolism $[44,45]$. Traditionally, alcohol consumption among African women is less common compared with those in developed countries. However, as women in Africa are increasingly influenced by western cultures and begin to change their lifestyle and as the populations in African countries are becoming more affluent, more and more women may be exposed to alcohol $[29,46,47]$. Few studies have investigated this relationship among African women [1]. Our study is the first multi-country study using a large African women sample. The incidence of breast cancer is anticipated to increase in African countries such as in Nigeria [48].

Our study also found that women who were past drinkers $(54 \%$ increase) had almost the same elevated risk as women who were current drinkers $(71 \%$ increase). Our study showed a doseresponse relationship between duration of alcohol drinking and breast cancer risk; women who drank for 20 years or longer had almost twice the odds of being cancer cases compared with nondrinkers. This relationship was confirmed in some studies [12,49] but not in others [12,43]. We did not find dose-response relationship between amount of alcohol intake and breast cancer risk, possibly because there were few heavy drinkers in our study population. Studies have suggested that a moderate level of alcohol consumption (e.g., 5-10 g/day) may be sufficient for increasing breast cancer risk $[50,51,52]$, while other studies did not show that low-level consumption of alcohol increases breast cancer risk in premenopausal women [53].

The effect of alcohol drinking among nulliparous women was significantly elevated compared to that among parous women. This result is consistent with prior studies which suggests that the carcinogenic effect of alcohol consumption is strongest between menarche and the first full term pregnancy and could be implicated in both increased risk of breast cancer and benign breast disease $[54,55,56]$. Starting to drink at a young reproductive age $(<30$ year, particularly during $25-29$ years) was associated with an increased risk of breast cancer in our study sample. This finding is consistent with other studies $[43,57,58,59]$.

In addition, alcohol drinking among women with BMI $>25 \mathrm{~kg} /$ $\mathrm{m}^{2}$, clinically defined as overweight or obese, had a greater risk of developing breast cancer. This suggests that obesity and alcohol drinking may have joint effects on risk of breast cancer among women. Being overweight or obese has been shown to be a risk factor for postmenopausal breast cancer $[60,61]$. The proposed mechanism in both animal models and humans of the mediating 
Table 3. Multivariable logistic regression analyses of alcohol consumption and breast cancer risk among women in Nigeria, Cameroon and Uganda, 1998-2013, using data after multiple imputation ( $\mathrm{N}=4727)$.

\begin{tabular}{|c|c|c|c|c|}
\hline \multirow[t]{2}{*}{ Variable } & \multirow{2}{*}{$\frac{\text { Nigeria }}{\text { Adjusted OR }}$} & \multirow{2}{*}{$\frac{\text { Cameroon }}{\text { Adjusted OR }}$} & \multirow{2}{*}{$\begin{array}{l}\text { Uganda } \\
\text { Adjusted OR }\end{array}$} & \multirow{2}{*}{$\frac{\text { Overall }}{\text { Adjusted OR }}$} \\
\hline & & & & \\
\hline & $(95 \% \mathrm{Cl})^{\dagger}$ & $(95 \% \mathrm{Cl})^{\dagger}$ & $(95 \% \mathrm{Cl})^{\dagger}$ & $(95 \% \mathrm{Cl})^{\ddagger}$ \\
\hline \multicolumn{5}{|l|}{ Ever drank alcohol } \\
\hline No & 1.0 (ref.) & 1.0 (ref.) & 1.0 (ref.) & 1.0 (ref.) \\
\hline Yes & $1.80(1.38-2.35)$ & $1.80(1.11-2.92)$ & $1.00(0.62-1.62)$ & $1.62(1.33-1.97)$ \\
\hline \multicolumn{5}{|l|}{ Status of drinking } \\
\hline Never & 1.0 (ref.) & 1.0 (ref.) & 1.0 (ref.) & 1.0 (ref.) \\
\hline Past & $1.88(1.33-2.67)$ & $1.00(0.45-2.23)$ & $0.99(0.57-1.75)$ & $1.54(1.19-2.00)$ \\
\hline Current & $1.70(1.13-2.55)$ & $2.17(1.28-3.69)$ & $1.01(0.55-1.85)$ & $1.71(1.30-2.23)$ \\
\hline \multicolumn{5}{|l|}{ Age at first drink, year } \\
\hline Never drank & 1.0 (ref.) & 1.0 (ref.) & 1.0 (ref.) & 1.0 (ref.) \\
\hline$\leq 18$ & $2.34(1.14-4.80)$ & $1.21(0.49-2.96)$ & $1.09(0.53-2.23)$ & $1.68(1.11-2.54)$ \\
\hline $19-24$ & $1.94(1.20-3.14)$ & $1.59(0.80-3.16)$ & $0.95(0.46-1.93)$ & $1.74(1.26-2.41)$ \\
\hline 25-29 & $1.53(0.91-2.56)$ & $4.09(1.63-10.2)$ & $0.81(0.31-2.11)$ & $1.77(1.20-2.61)$ \\
\hline$\geq 30$ & $1.72(1.10-2.69)$ & $1.47(0.67-3.21)$ & $1.09(0.53-2.24)$ & $1.39(1.01-1.91)$ \\
\hline$P$-value for trend & $<0.001$ & 0.08 & 0.99 & $<0.001$ \\
\hline \multicolumn{5}{|c|}{ Duration of alcohol drinking, year } \\
\hline Never & 1.0 (ref.) & 1.0 (ref.) & 1.0 (ref.) & 1.0 (ref.) \\
\hline Drank & $1.35(0.92-1.99)$ & $1.25(0.513 .05)$ & $0.94(0.49-1.80)$ & $1.41(1.04-1.91)$ \\
\hline 10-19 & $1.90(1.22-2.97)$ & $1.63(0.75-2.74)$ & $1.16(0.52-2.57)$ & $1.71(1.23-2.39)$ \\
\hline$\geq 20$ & $2.97(1.66-5.31)$ & $2.30(1.19-4.45)$ & $0.99(0.49-2.00)$ & $1.82(1.30-2.54)$ \\
\hline$P$-value for trend & $<0.001$ & 0.002 & 0.85 & $<0.001$ \\
\hline Per 10-year increase & $1.84(1.43-2.37)$ & $1.85(1.24-2.75)$ & $1.04(0.68-1.60)$ & $1.54(1.29-1.84)$ \\
\hline \multicolumn{5}{|l|}{$\begin{array}{l}\text { Average amount of alcohol } \\
\text { consumed daily, gram }\end{array}$} \\
\hline Never drank & 1.0 (ref.) & 1.0 (ref.) & 1.0 (ref.) & 1.0 (ref.) \\
\hline $0.1-4.9$ & $2.27(1.33-3.87)$ & $2.62(1.31-5.20)$ & $0.99(0.53-1.87)$ & $1.82(1.31-2.54)$ \\
\hline $5.0-9.9$ & $1.91(1.23-2.96)$ & $1.31(0.65-2.64)$ & $0.72(0.31-1.69)$ & $1.52(1.10-2.11)$ \\
\hline$\geq 10$ & $1.37(0.85-2.22)$ & $1.61(0.77-3.35)$ & $1.48(0.58-3.80)$ & $1.50(1.04-2.18)$ \\
\hline$P$-value for trend & 0.03 & 0.13 & 0.57 & 0.007 \\
\hline Per $10 \mathrm{~g}$ increase & $1.43(1.05-1.96)$ & $1.50(0.89-2.52)$ & $1.20(0.63-2.28)$ & $1.39(1.09-1.76)$ \\
\hline \multicolumn{5}{|c|}{ Life-time alcohol consumption, gram-years } \\
\hline Never & 1.0 (ref.) & 1.0 (ref.) & 1.0 (ref.) & 1.0 (ref.) \\
\hline Drank & $1.24(0.79-1.94)$ & $1.24(0.38-4.04)$ & $0.90(0.44-1.83)$ & $1.29(0.91-1.83)$ \\
\hline $30.0-79.9$ & $2.61(1.49-4.58)$ & $2.21(0.96-5.11)$ & $0.76(0.32-1.82)$ & $1.85(1.26-2.72)$ \\
\hline 80.0-159.9 & $2.11(1.13-3.93)$ & $1.96(0.88-4.41)$ & $0.81(0.33-1.98)$ & $1.73(1.15-2.60)$ \\
\hline$\geq 160.0$ & $1.87(1.01-3.45)$ & $1.67(0.83-3.36)$ & $1.98(0.75-5.26)$ & $1.76(1.17-2.64)$ \\
\hline$P$-value for trend & 0.001 & 0.06 & 0.19 & 0.001 \\
\hline Per 100 gram-year increase & $1.45(1.16-1.81)$ & $1.29(0.99-1.70)$ & $1.26(0.89-1.77)$ & $1.29(1.12-1.51)$ \\
\hline \multicolumn{5}{|l|}{ Type of alcohol $\mathbb{1}$} \\
\hline Never drank & 1.0 (ref.) & 1.0 (ref.) & 1.0 (ref.) & 1.0 (ref.) \\
\hline Beer & $1.80(1.35-2.40)$ & $1.51(0.92-2.46)$ & $0.88(0.48-1.61)$ & $1.53(1.22-1.91)$ \\
\hline Wine & $2.32(1.20-4.50)$ & $1.01(0.52-1.98)$ & $1.11(0.58-2.13)$ & $1.32(0.91-1.92)$ \\
\hline Spirits & $1.76(0.89-3.48)$ & $1.31(0.58-2.95)$ & $1.30(0.64-2.67)$ & $1.52(0.99-2.32)$ \\
\hline
\end{tabular}

${ }^{\dagger}$ Adjusted for age at diagnosis or interview (categorical), ethnicity, education (categorical), age at menarche (categorical), number of live births (categorical), age at first live birth (categorical), menopausal status, family history of breast cancer, benign breast disease, hormonal contraceptive use, BMI (continuous), and height (continuous);

${ }^{\ddagger}$ Adjusted for the above variables and study site.

IIncludes drinkers who drink a combination of alcoholic beverages.

doi:10.1371/journal.pone.0106908.t003 
effect of alcohol as well as adiposity's effect on serum estradiol and insulin levels may account for the interaction effect observed between BMI and alcohol consumption [62,63].

Heterogeneity in the level of alcohol consumption was observed among women in three African countries. Using a definition of alcohol drinking as having at least one drink every week for a continuous 6 months or more, the percentage of ever drinkers in Nigeria, Cameroon, and Uganda were $5.0 \%, 34.6 \%$, and $50.0 \%$, respectively. This is in line with previous surveys of alcohol consumption in the three countries, although it is not straightforward to directly compare with previous studies due to different definition of alcohol drinking. According to the WHO country surveys conducted from 2003 to 2005, the percent of women who are lifetime abstainers in Nigeria, Cameroon, and Uganda were $50.9 \%, 39.8 \%, 36.7 \%$, respectively $[64,65,66]$. Heterogeneity in the relationship between alcohol drinking and breast cancer was also observed across the three countries. In Nigeria and Cameroon, women who drank alcohol had a moderate increased risk of breast cancer compared to never-drinkers, whereas in Uganda there was only a marginal increase in risk. A small sample size $(n=380)$ may explain for these non-significant findings in Uganda. A previous study found that a larger proportion of Nigerian women who drank alcohol regularly tended to be heavy drinkers compared to Ugandan women [29], which may also account for the weak correlation between alcohol consumption and breast cancer risk for women in Uganda. Larger sample size in Uganda and Cameroon are desirable to confirm these study findings.

Although some studies have suggested that recall bias only had minor effects on alcohol reporting and on the estimation of risk for breast cancer [67], we could not exclude the possibility of recall bias in reporting alcohol consumption in our study. Due to the retrospective nature of the study, participants might have difficulty in recalling alcohol consumption patterns, especially if the patterns changed over time for older women. In addition, cultural stigmas against alcohol use among women might also have resulted in

Table 4. Stratified analyses of alcohol consumption and breast cancer risk among women in Nigeria, Cameroon, and Uganda using data after multiple imputation, 1998-2013.

\begin{tabular}{|c|c|c|c|c|}
\hline Stratified variable & $\begin{array}{l}\text { Number of } \\
\text { participants }\end{array}$ & $\begin{array}{l}\text { Number and prevalence } \\
\text { of ever-drinkers, } \mathbf{n}(\%)\end{array}$ & $\begin{array}{l}\text { Adjusted OR for being ever-drinkers } \\
\text { vs. non-drinkers }(95 \% \mathrm{Cl}) *\end{array}$ & $\begin{array}{l}P \text {-value for } \\
\text { interaction }\end{array}$ \\
\hline \multicolumn{5}{|c|}{ Age at interview or diagnosis, year } \\
\hline$<50$ & 3,047 & $384(12.6)$ & $1.64(1.28-2.11)$ & \\
\hline$\geq \mathbf{5 0}$ & 1,680 & $293(17.4)$ & $1.97(1.42-2.73)$ & 0.49 \\
\hline \multicolumn{5}{|l|}{ Menopausal status } \\
\hline Premenopausal & 2,948 & $376(12.8)$ & $1.64(1.26-2.12)$ & \\
\hline Post-menopausal & 1,779 & $301(16.9)$ & $1.82(1.32-2.52)$ & 0.14 \\
\hline \multicolumn{5}{|l|}{ Parity } \\
\hline Nulliparous & 489 & $68(13.9)$ & $2.81(1.24-6.35)$ & \\
\hline Parous & 4,238 & $609(14.4)$ & $1.55(1.26-1.91)$ & 0.03 \\
\hline \multicolumn{5}{|c|}{ Family history of breast cancer } \\
\hline Yes & 261 & $85(32.6)$ & $2.66(1.08-6.57)$ & \\
\hline No & 4,466 & $592(13.3)$ & 1.59 (1.29-1.96) & 0.67 \\
\hline \multicolumn{5}{|l|}{ Benign breast disease } \\
\hline Yes & 375 & $86(22.9)$ & $2.43(1.25-4.75)$ & \\
\hline No & 4,352 & $591(13.6)$ & $1.56(1.26-1.93)$ & 0.11 \\
\hline \multicolumn{5}{|c|}{ Ever use of hormonal contraceptives } \\
\hline Yes & 1,500 & $294(19.6)$ & $1.48(1.09-2.02)$ & \\
\hline No & 3,227 & $383(11.9)$ & $1.73(1.32-2.27)$ & 0.58 \\
\hline \multicolumn{5}{|c|}{ Body mass index, $\mathrm{kg} / \mathrm{m}^{2}$} \\
\hline$\leq \mathbf{2 5}$ & 2,209 & $292(13.2)$ & $1.09(0.79-1.50)$ & \\
\hline$>\mathbf{2 5}$ & 2,518 & $385(15.3)$ & $2.06(1.59-2.68)$ & 0.03 \\
\hline \multicolumn{5}{|l|}{ Height, cm } \\
\hline$\leq 160$ & 2,510 & $286(11.4)$ & $1.64(1.23-2.20)$ & \\
\hline$>160$ & 2,217 & $391(17.6)$ & $1.72(1.29-2.29)$ & 0.11 \\
\hline \multicolumn{5}{|c|}{ Age at menarche, year } \\
\hline$\leq 15$ & 2,943 & $442(15.0)$ & $1.71(1.33-2.20)$ & \\
\hline$>15$ & 1,784 & $235(13.2)$ & $1.55(1.09-2.21)$ & 0.86 \\
\hline \multicolumn{5}{|l|}{ Ethnicity } \\
\hline Yoruba & 3,104 & $217(7.0)$ & $1.51(1.12-2.04)$ & \\
\hline Other & 1,623 & $460(28.3)$ & $1.62(1.27-2.07)$ & 0.81 \\
\hline
\end{tabular}

*Adjusted for all other variables listed in this table as well as age at first live birth and study site.

doi:10.1371/journal.pone.0106908.t004 
under-reporting of alcohol consumption [68,69,70]. Nigerian women might tend to under-report alcohol consumption, as it is often considered culturally inappropriate for them to drink alcohol outside of religious settings [70]. The majority of subjects in the study were considered to be light drinkers whereas there were few moderate and heavy drinkers. This observation could also account for the lack of a dose-response relationship with respect to the amount of alcohol consumed. Our study did not assess alcohol consumption at each stage of a woman's life, and therefore, it was assumed that alcohol consumption was constant over a subject's lifetime. Since ethanol and its primary metabolite, acetaldehyde, can affect estrogen levels and are involved in carcinogenic pathways [71], alcohol consumption later in life may further accelerate genetic mutations.

In conclusion, our study found a positive relationship between alcohol consumption and breast cancer risk among sub-Saharan African women. The adoption of a Western lifestyle and erosion of many traditional customs that prohibited alcohol drinking has led to drastic changes in alcohol consumption patterns, including greater drinking among young people and women [72,73,74]. According to the $2011 \mathrm{WHO}$ data, $25.3 \%$ of the population in Africa is displaying an increase in five-year trends for recorded adult per capita alcohol consumption [75]. Surveys from 2005 also show that in Nigeria and Uganda, total adult (defined as 15 years or older) per capita alcohol consumption (10.00-12.49 liters) has already exceeded the per capita alcohol consumption in the United States (7.50-9.99) [75]. If we assumed a common odds

\section{References}

1. Adebamowo CA, Adekunle OO (1999) Case-controlled study of the epidemiological risk factors for breast cancer in Nigeria. Br J Surg 86: 665-668.

2. Adebamowo CA, Ajayi OO (2000) Breast cancer in Nigeria. West Afr J Med 19: 179-191.

3. Hutchinson L (2010) Breast cancer: challenges, controversies, breakthroughs. Nat Rev Clin Oncol 7: 669-670.

4. Anothaisintawee T, Wiratkapun C, Lerdsitthichai P, Kasamesup V, Wongwaisayawan S, et al. (2013) Risk factors of breast cancer: a systematic review and meta-analysis. Asia Pac J Public Health 25: 368-387.

5. Warner E (2011) Clinical practice. Breast-cancer screening. N Engl J Med 365: 1025-1032.

6. Jemal A, Ward E, Thun MJ (2007) Recent trends in breast cancer incidence rates by age and tumor characteristics among U.S. women. Breast Cancer Res 9: R28.

7. Parkin DM, Sitas F, Chirenje M, Stein L, Abratt R, et al. (2008) Part I: Cancer in Indigenous Africans - burden, distribution, and trends. Lancet Oncol 9: 683692

8. Sitas F, Parkin DM, Chirenje M, Stein L, Abratt R, et al. (2008) Part II: Cancer in Indigenous Africans - causes and control. Lancet Oncol 9: 786-795.

9. Suzuki R, Orsini N, Mignone L, Saji S, Wolk A (2008) Alcohol intake and risk of breast cancer defined by estrogen and progesterone receptor status - a metaanalysis of epidemiological studies. Int J Cancer 122: 1832-1841.

10. Hamajima N, Hirose K, Tajima K, Rohan T, Calle EE, et al. (2002) Alcohol, tobacco and breast cancer - collaborative reanalysis of individual data from 53 epidemiological studies, including 58,515 women with breast cancer and 95,067 women without the disease. Br J Cancer 87: 1234-1245.

11. Key J, Hodgson S, Omar RZ, Jensen TK, Thompson SG, et al. (2006) Metaanalysis of studies of alcohol and breast cancer with consideration of the methodological issues. Cancer Causes Control 17: 759-770.

12. Bowlin SJ, Leske MC, Varma A, Nasca P, Weinstein A, et al. (1997) Breast cancer risk and alcohol consumption: results from a large case-control study. Int J Epidemiol 26: 915-923.

13. Bagnardi V, Blangiardo M, La Vecchia C, Corrao G (2001) A meta-analysis of alcohol drinking and cancer risk. Br J Cancer 85: 1700-1705.

14. Nasca PC, Baptiste MS, Field NA, Metzger BB, Black M, et al. (1990) An epidemiological case-control study of breast cancer and alcohol consumption. Int J Epidemiol 19: 532-538.

15. Thun MJ, Peto R, Lopez AD, Monaco JH, Henley SJ, et al. (1997) Alcohol consumption and mortality among middle-aged and elderly U.S. adults. N Engl J Med 337: 1705-1714.

16. Kinney AY, Millikan RC, Lin YH, Moorman PG, Newman B (2000) Alcohol consumption and breast cancer among black and white women in North Carolina (United States). Cancer Causes Control 11: 345-357. ratio of 1.62 and observed alcohol prevalence in the three countries, $4.6 \%, 19.5 \%$, and $20.1 \%$ of breast cancer cases can be attributed to alcohol drinking in Nigeria, Cameroon, and Uganda, respectively. As breast cancer incidence is increasing in African countries and alcohol drinking is increasingly popular among African women [29,30,31,32,46,47], public health programs in Africa should take proactive measures to prevent breast cancer through addressing the modifiable risk factor of alcohol consumption, including providing current information on the risk of alcohol consumption among women and advocating proper regulation of alcohol sale through more effective alcohol policies $[76,77,78]$.

\section{Supporting Information}

Table S1 Multivariable logistic regression analyses of alcohol consumption and breast cancer risk among women in Nigeria, Cameroon and Uganda, 1998-2013: Complete case analysis $(N=4157)$. (DOC)

\section{Author Contributions}

Conceived and designed the experiments: NH OIO DH. Performed the experiments: TO NH PN AG JJ IMB CA AA OO OIO DH. Analyzed the data: FQ NH DH. Contributed reagents/materials/analysis tools: FQ NH CA OIO DH. Contributed to the writing of the manuscript: FQ TO NH PN AG JJ IMB CA AA OO OIO DH.

17. Llanos AA, Makambi KH, Tucker CA, Shields PG, Adams-Campbell LL (2012) Alcohol, anthropometrics, and breast cancer risk in African American women. Breast J 18: 394-395.

18. Chandran U, Zirpoli G, Ciupak G, McCann SE, Gong Z, et al. (2013) Does alcohol increase breast cancer risk in African-American women? Findings from a case-control study. British Journal of Cancer.

19. Zhang M, Holman CD (2011) Low-to-moderate alcohol intake and breast cancer risk in Chinese women. Br J Cancer 105: 1089-1095.

20. Baumgartner KB, Annegers JF, McPherson RS, Frankowski RF, Gilliland FD, et al. (2002) Is alcohol intake associated with breast cancer in Hispanic women? The New Mexico Women's Health Study. Ethn Dis 12: 460-469.

21. Yoo KY, Tajima K, Miura S, Takeuchi T, Hirose K, et al. (1997) Breast cancer risk factors according to combined estrogen and progesterone receptor status: a case-control analysis. Am J Epidemiol 146: 307-314.

22. McDonald JA, Mandel MG, Marchbanks PA, Folger SG, Daling JR, et al. (2004) Alcohol exposure and breast cancer: results of the women's contraceptive and reproductive experiences study. Cancer Epidemiol Biomarkers Prev 13: 2106-2116.

23. Bao PP, Shu XO, Gao YT, Zheng Y, Cai H, et al. (2011) Association of hormone-related characteristics and breast cancer risk by estrogen receptor/ progesterone receptor status in the shanghai breast cancer study. Am J Epidemiol 174: 661-671.

24. Nichols HB, Trentham-Dietz A, Love RR, Hampton JM, Hoang Anh PT, et al. (2005) Differences in breast cancer risk factors by tumor marker subtypes among premenopausal Vietnamese and Chinese women. Cancer Epidemiol Biomarkers Prev 14: 41-47.

25. Hiatt RA, Bawol RD (1984) Alcoholic beverage consumption and breast cancer incidence. Am J Epidemiol 120: 676-683.

26. Hiatt RA, Klatsky AL, Armstrong MA (1988) Alcohol consumption and the risk of breast cancer in a prepaid health plan. Cancer Res 48: 2284-2287.

27. Brinton LA, Benichou J, Gammon MD, Brogan DR, Coates R, et al. (1997) Ethnicity and variation in breast cancer incidence. Int J Cancer 73: 349-355.

28. Zhu K, Davidson NE, Hunter S, Yang X, Payne-Wilks K, et al. (2003) Methylgroup dietary intake and risk of breast cancer among African-American women: a case-control study by methylation status of the estrogen receptor alpha genes. Cancer Causes Control 14: 827-836.

29. Martinez P, Roislien J, Naidoo N, Clausen T (2011) Alcohol abstinence and drinking among African women: data from the World Health Surveys. BMC Public Health 11: 160

30. Ibanga A, Adetula AV, Dagona Z, Karick H, Ojiji O (2005) The contexts of alcohol consumption by men and women in Nigeria. In: Obot I, Room R, editors. Alcohol, Gender and Drinking Problems: perspectives from low and middle income countries. 1st ed. Geneva: World Health Organization. pp. 143166. 
31. Tumwesigye NM, Kasirye R (2005) Gender and the major consequences of alcohol consumption in Uganda. In: Obot I, Room R, editors. Alcohol, Gender and Drinking Problems: perspectives from low and middle income countries. 1st ed. Geneva: World Health Organization. pp. 189-208.

32. Mamman LS, Brieger WR, Oshiname FO (2002) Alcohol consumption pattern among women in a rural Yoruba community in Nigeria. Subst Use Misuse 37: 579-597.

33. Smith-Warner SA, Spiegelman D, Yaun SS, van den Brandt PA, Folsom AR, et al. (1998) Alcohol and breast cancer in women: a pooled analysis of cohort studies. JAMA 279: 535-540.

34. Huo D, Kim H-J, Adebamowo CA, Ogundiran TO, Akang EE, et al. (2007) Genetic polymorphisms in uridine diphospho-glucuronosyltransferase $1 \mathrm{~A} 1$ and breast cancer risk in Africans. Breast Cancer Research and Treatment 110: 367376.

35. Huo D, Adebamowo CA, Ogundiran TO, Akang EE, Campbell O, et al. (2008) Parity and breastfeeding are protective against breast cancer in Nigerian women. British Journal of Cancer 98: 992-996.

36. Hou N, Ogundiran T, Ojengbede O, Morhason-Bello I, Zheng Y, et al. (2013) Risk factors for pregnancy-associated breast cancer: a report from the Nigerian Breast Cancer Study. Ann Epidemiol 23: 551-557.

37. van Buuren S, Boshuizen HC, Knook DL (1999) Multiple imputation of missing blood pressure covariates in survival analysis. Stat Med 18: 681-694.

38. Horton NJ, Kleinman KP (2007) Much ado about nothing: A comparison of missing data methods and software to fit incomplete data regression models. Am Stat 61: 79-90.

39. Rubin DB (1987) Multiple Imputation for Nonresponse in Surveys. New York: John Wiley \& Sons, Inc.

40. Seitz HK, Pelucchi C, Bagnardi V, La Vecchia C (2012) Epidemiology and pathophysiology of alcohol and breast cancer: Update 2012. Alcohol Alcohol 47: 204-212.

41. Kushi LH, Doyle C, McCullough M, Rock CL, Demark-Wahnefried W, et al. (2012) American Cancer Society Guidelines on nutrition and physical activity for cancer prevention: reducing the risk of cancer with healthy food choices and physical activity. CA Cancer J Clin 62: 30-67.

42. Chandran U, Hirshfield KM, Bandera EV (2012) The role of anthropometric and nutritional factors on breast cancer risk in African-American women. Public Health Nutr 15: 738-748.

43. Park SY, Kolonel LN, Lim U, White KK, Henderson BE, et al. (2013) Alcohol consumption and breast cancer risk among women from five ethnic groups with light to moderate intakes: The Multiethnic Cohort Study. Int J Cancer

44. Dumitrescu RG, Shields PG (2005) The etiology of alcohol-induced breast cancer. Alcohol 35: 213-225.

45. McCarver DG, Byun R, Hines RN, Hichme M, Wegenek W (1998) A genetic polymorphism in the regulatory sequences of human CYP2E1: association with increased chlorzoxazone hydroxylation in the presence of obesity and ethanol intake. Toxicol Appl Pharmacol 152: 276-281.

46. Francis JM, Grosskurth H, Changalucha J, Kapiga SH, Weiss HA (2014) Systematic review and meta-analysis: prevalence of alcohol use among young people in eastern Africa. Trop Med Int Health.

47. Peer N, Lombard C, Steyn K, Levitt N (2014) Rising alcohol consumption and a high prevalence of problem drinking in black men and women in Cape Town: the CRIBSA study. J Epidemiol Community Health.

48. Akarolo-Anthony SN, Ogundiran TO, Adebamowo CA (2010) Emerging breast cancer epidemic: evidence from Africa. Breast Cancer Res 12 Suppl 4: S8.

49. Wu AH, Vigen C, Razavi P, Tseng CC, Stancyzk FZ (2012) Alcohol and breast cancer risk among Asian-American women in Los Angeles County. Breast Cancer Res 14: R151.

50. Willett WC, Stampfer MJ, Colditz GA, Rosner BA, Hennekens CH, et al. (1987) Moderate alcohol consumption and the risk of breast cancer. N Engl J Med 316: 1174-1180

51. Chen WY, Rosner B, Hankinson SE, Colditz GA, Willett WC (2011) Moderate alcohol consumption during adult life, drinking patterns, and breast cancer risk. JAMA 306: 1884-1890.

52. Longnecker MP, Newcomb PA, Mittendorf R, Greenberg ER, Clapp RW, et al, (1995) Risk of breast cancer in relation to lifetime alcohol consumption. J Natl Cancer Inst 87: 923-929.

53. Garland M, Hunter DJ, Colditz GA, Spiegelman DL, Manson JE, et al. (1999) Alcohol consumption in relation to breast cancer risk in a cohort of United States women 25-42 years of age. Cancer Epidemiol Biomarkers Prev 8: 10171021.
54. Colditz GA, Frazier AL (1995) Models of breast cancer show that risk is set by events of early life: prevention efforts must shift focus. Cancer Epidemiol Biomarkers Prev 4: 567-571.

55. Liu Y, Colditz GA, Rosner B, Berkey CS, Collins LC, et al. (2013) Alcohol intake between menarche and first pregnancy: a prospective study of breast cancer risk. J Natl Cancer Inst 105: 1571-1578.

56. Liu Y, Tamimi RM, Berkey CS, Willett WC, Collins LC, et al. (2012) Intakes of alcohol and folate during adolescence and risk of proliferative benign breast disease. Pediatrics 129: e1192-1198.

57. Harvey EB, Schairer C, Brinton LA, Hoover RN, Fraumeni JF Jr. (1987) Alcohol consumption and breast cancer. J Natl Cancer Inst 78: 657-661.

58. Schatzkin A, Jones DY, Hoover RN, Taylor PR, Brinton LA, et al. (1987) Alcohol consumption and breast cancer in the epidemiologic follow-up study of the first National Health and Nutrition Examination Survey. N Engl J Med 316: 1169-1173.

59. Young TB (1989) A case-control study of breast cancer and alcohol consumption habits. Cancer 64: 552-558.

60. Key TJ, Appleby PN, Reeves GK, Roddam A, Dorgan JF, et al. (2003) Body mass index, serum sex hormones, and breast cancer risk in postmenopausal women. J Natl Cancer Inst 95: 1218-1226.

61. Rinaldi S, Key TJ, Peeters PH, Lahmann PH, Lukanova A, et al. (2006) Anthropometric measures, endogenous sex steroids and breast cancer risk in postmenopausal women: a study within the EPIC cohort. Int J Cancer 118: 2832-2839.

62. Hong J, Holcomb VB, Dang F, Porampornpilas K, Nunez NP (2010) Alcohol consumption, obesity, estrogen treatment and breast cancer. Anticancer Res 30: $1-8$.

63. Hvidtfeldt UA, Gunter MJ, Lange T, Chlebowski RT, Lane D, et al. (2012) Quantifying mediating effects of endogenous estrogen and insulin in the relation between obesity, alcohol consumption, and breast cancer. Cancer Epidemiol Biomarkers Prev 21: 1203-1212.

64. WHO (2005) World Health Organization Global Status Report on Alcohol 2004. Country Profiles, Africa - Uganda. WHO.

65. WHO (2005) World Health Organization Global Status Report on Alcohol 2004. Country Profiles, Africa - Nigeria. WHO.

66. WHO (2005) World Health Organization Global Status Report on Alcohol 2004. Country Profiles, Africa - Cameroon. WHO

67. Giovannucci E, Stampfer MJ, Colditz GA, Manson JE, Rosner BA, et al. (1993) Recall and selection bias in reporting past alcohol consumption among breast cancer cases. Cancer Causes Control 4: 441-448.

68. Stockwell T, Donath S, Cooper-Stanbury M, Chikritzhs T, Catalano P, et al. (2004) Under-reporting of alcohol consumption in household surveys: a comparison of quantity-frequency, graduated-frequency and recent recall. Addiction 99: 1024-1033.

69. Ernhart CB, Morrow-Tlucak M, Sokol RJ, Martier S (1988) Underreporting of alcohol use in pregnancy. Alcohol Clin Exp Res 12: 506-511.

70. Ikuesan BA (1994) Drinking problems and the position of women in Nigeria. Addiction 89: 941-944; discussion 951-960.

71. Seitz HK, Maurer B (2007) The relationship between alcohol metabolism, estrogen levels, and breast cancer risk. Alcohol Res Health 30: 42-43.

72. Dumbili E (2013) Changing patterns of alcohol consumption in Nigeria: an exploration of responsible factors and consequences. Medical Sociology Online 7: $20-33$.

73. Chikere EI, Mayowa MO (2011) Prevalence and perceived health effect of alcohol use among male undergraduate students in Owerri, South-East Nigeria: a descriptive cross-sectional study. BMC Public Health 11: 118.

74. Ramsoomar L, Morojele NK (2012) Trends in alcohol prevalence, age of initiation and association with alcohol-related harm among South African youth: implications for policy. S Afr Med J 102: 609-612.

75. WHO (2011) Global status report on alcohol and health. Geneva: WHO. $1-286 \mathrm{p}$.

76. Adebamowo CA, Akarolo-Anthony S (2009) Cancer in Africa: opportunities for collaborative research and training. Afr J Med Med Sci 38 Suppl 2: 5-13.

77. Lawhon M, Herrick C (2013) Alcohol control in the news: the politics of media representations of alcohol policy in South Africa. J Health Polit Policy Law 38: 987-1021.

78. Parry C, Burnhams NH, London L (2012) A total ban on alcohol advertising: presenting the public health case. S Afr Med J 102: 602-604. 